\title{
Clinical Performance of Bulk-Fill Resin Composite Restorations Using the United States Public Health Service and Federation Dentaire Internationale Criteria: A 12-Month Randomized Clinical Trial
}

\author{
Márcia de Almeida Durão ${ }^{1, \odot}$ Ana Karina Maciel de Andrade ${ }^{2, \odot} \quad$ Maria do Carmo Moreira da Silva Santos ${ }^{1, \odot}$ \\ Marcos Antônio Japiassú Resende Montes ${ }^{1, \odot}$ Gabriela Queiroz de Melo Monteiro ${ }^{1, \odot}$
}

${ }^{1}$ School of Dentistry, University of Pernambuco, Avenida Agamenon Magalhães, S/N - Santo Amaro - Recife - PE, Brazil

2Department of Restorative Dentistry, Dental School, Universidade Federal da Paraíba, Cidade Universitária, Brazil
Address for correspondence Márcia de A. Durão, PhD, School of Dentistry, University of Pernambuco, Avenida Agamenon Magalhães, S/N - Santo Amaro, Recife, PE 50100-010, Brazil (e-mail: marciadurao.fop@gmail.com).

Abstract

Keywords
- dental restoration
failure
- permanent dental
restoration
- direct restoration
- posterior teeth
- resin composite
- bulk-fill resin
composite
- randomized controlled
trial

Objective This study was aimed to compare the 12-month clinical performance of two full-body bulk-fill resin composites Filtek bulk fill/3M ESPE (FBF) and Tetric EvoCeram bulk fill/Ivoclar Vivadent (TBF) and a conventional microhybrid resin composite Filtek Z250/3M ESPE (Z250) using the modified the United States Public Health Service (USPHS) and Federation Dentaire Internationale (FDI) criteria. Also, the agreement between the two evaluation criteria was evaluated at baseline and after 12 months of follow-up.

Materials and Methods A total of 138 class I and II restorations were placed in posterior teeth (split-mouth design) of 46 volunteers following manufacturer's instructions and bonded with a self-etching bonding agent (Clear fill SE Bond/Kuraray). The restorations were evaluated at baseline and after 12 months of follow-up by three previously calibrated dentists (Cohen's $K=0.84$ ).

Statistical Analysis Fisher's exact test and Pearson's Chi-squared test were used to evaluating the homogeneity of distribution of the clinical characteristics. Friedman's test was applied to evaluate differences among the resin composites. The results obtained for the USPHS and FDI criteria at the different observation times were compared using the Wilcoxon test. A level of significance of 0.05 was adopted for all tests. Results After 12 months (recall rate, $78.3 \%, n=36$ patients), the overall success rate was $99.07 \%$ for both criteria. Only one failed restoration $(0.93 \%)$ was detected for each system during follow-up in the TBF group.

Conclusion The bulk-fill resin composites showed satisfactory clinical performance compared with conventional resin composite after 12 months. The percentage of the acceptable scores was significantly higher for the USPHS criteria, due to discrepancies in the score description for each criterion. published online

November 26, 2020
DOI https://doi.org/ 10.1055/s-0040-1718639 ISSN 1305-7456.
(C) 2020. European Journal of Dentistry.

This is an open access article published by Thieme under the terms of the Creative Commons Attribution-NonDerivative-NonCommercial-License, permitting copying and reproduction so long as the original work is given appropriate credit. Contents may not be used for commercial purposes, or adapted, remixed, transformed or built upon. (https://creativecommons.org/licenses/by-nc-nd/4.0/)

Thieme Medical and Scientific Publishers Pvt. Ltd., A-12, 2nd Floor, Sector 2, Noida-201301 UP, India 


\section{Introduction}

Bulk-fill resin composites have been introduced into the market for restorations in posterior teeth. The main characteristic of these materials is their insertion in single-increment applications of 4 to $5 \mathrm{~mm}^{1-3}$

Low-viscosity bulk-fill resin composites were the first materials developed. These flowable materials are indicated as a restorative base and require a 2 -mm thick covering layer with a regular/conventional resin composite., ${ }^{2,45}$ Subsequently, paste-like "full-body" bulk-fill restorative resin composites were introduced. These materials contain a higher percentage of inorganic filler, which allows their use in high-masticatory load-bearing areas without the need of coverage.,5-8 Bulk-fill resin composites consist of conventional methacrylate monomers. Low-polymerization shrinkage stress and improved physical and mechanical properties can be achieved by incorporating prepolymerized particles and modified monomers. These particles act as chemical modulators of the polymerization reaction, ${ }^{9-11}$ such as aromatic urethane dimethacrylate (AUDMA) ${ }^{12}$ and addition fragmentation monomers (AFM), incorporated into Filtek bulk fill. ${ }^{13}$ In general, this class of materials has a high translucency to ensure a greater depth of cure. ${ }^{9,11,14,15}$ Other manufacturers added alternative photoinitiators other than camphorquinone. The Tetric EvoCeram bulk-fill resin composite contains the Ivocerin (dibenzoyl germanium derivative) and TPO (mono-alkyl phosphine oxide) photoinitiators to increase the light-curing capacity of the resin..$^{12,16,17}$

Laboratory studies reported satisfactory results in terms of the physical properties of bulk-fill resin composites similar to those of conventional composites inserted by the incremental technique. ${ }^{8,10,18-21}$ However, due to the short time on the market, only a few clinical studies regarding the long-term behavior of these materials are available. The systematic review by Veloso et al pointed to dental and material fractures as the leading causes of failures, considering the majority due to bruxism..$^{22}$ One-year clinical evaluations of different types of bulk-fill resin composites, related failures in marginal adaptation with the incidence of secondary caries, and contamination with saliva during the restorative procedure were studied. ${ }^{23}$

Different clinical criteria are used for the evaluation of dental restorations. The United States Public Health Service (USPHS) criteria, also known as the Ryge criteria, ${ }^{24}$ is the most widely used. ${ }^{25}$ In 2007 , a new system for evaluating the clinical performance of dental restorations was introduced, known as the criteria of the Federation Dentaire Internationale (FDI). ${ }^{26,27}$ This criterion is divided into three main categories that evaluate esthetic, functional, and biological properties by attributing a score that ranges from 1 to $5 . .^{28-30}$

Within this context, the objective of this study was to evaluate and compare the effectiveness of restorations performed with two full-body bulk-fill resin composites and a conventional resin composite. The materials were inserted into class I and II cavities and observed for 12 months using the modified USPHS and FDI criteria. The agreement between the two criteria was also assessed. Two null hypotheses were tested as follows: (1) the clinical effectiveness of the materials does not differ over the studied period, and
(2) the evaluation criteria do not provide divergent results for the common categories.

\section{Materials and Methods}

\section{Study Design}

A controlled, double-blind (evaluator and patient), randomized clinical trial with three study groups with an equal allocation ratio (split-mouth design) was conducted. The study was approved by the Ethics Committee on Research Involving Humans of the University of Pernambuco, Brazil (protocol no. 944.518). The study was registered with the Brazilian Registry of Clinical Trials (ReBEC, RBR-5v6dsj) and was conducted following the Consolidated Standards of Reporting Trials (CONSORT).

\section{Population and Sample Size}

Adolescents aged 12 to 18 years (mean age of 14.82 ) regularly enrolled in three public schools of Camaragibe and Recife, Pernambuco, Brazil, who required dental treatment were recruited. Most of these adolescents live in poor, low-income communities without guidance and access to healthy food and oral hygiene or dental services. This population was chosen since it represents the social reality of this region, and the study may make a social contribution.

The sample size was 46 restorations per group to detect differences in the outcomes assuming a significance level of $5 \%$ and power of the study of $80 \%$. The sample size was calculated using previous studies that evaluated restorations in posterior teeth. ${ }^{31-33}$ Study designs that enable the evaluation of groups of materials with similar intraindividual comparisons have found significant differences for this sample size. ${ }^{34}$

\section{Eligibility Criteria}

The following inclusion criteria were adopted: (1) the presence of three vital posterior teeth with primary caries or that require the replacement of class I and II restorations, (2) absence of parafunctional habits, (3) absence of noncarious cervical lesions in the evaluated teeth, (4) the presence of occlusal and proximal contacts, (5) good general health, (6) absence of any contraindication for dental treatment, and (7) good recall availability.

Criteria for exclusion were as follows: (1) advanced periodontal disease, (2) posterior teeth with pulp alterations or endodontically treated, (3) posterior teeth with carious lesions on surfaces other than the cavity used for this study, (4) teeth with any symptomatology, (5) smoking, and (6) lack of adjacent and antagonist teeth. All patients participated voluntarily, and the adolescents and their legal representatives signed the free, informed consent form.

\section{Randomization, Allocation, and Blinding}

A total of 138 restorations from 46 volunteers were performed by the same operator ( - Fig. 1). Each patient received three restorations, each performed with one of the three

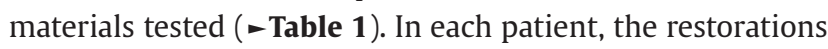
were started in the most posterior tooth with the largest cavity. After cavity preparation and rubber dam isolation, opaque sealed envelopes were used to randomize the resin composite to be inserted in each tooth. The patients were unaware of the type of material used in each tooth. 


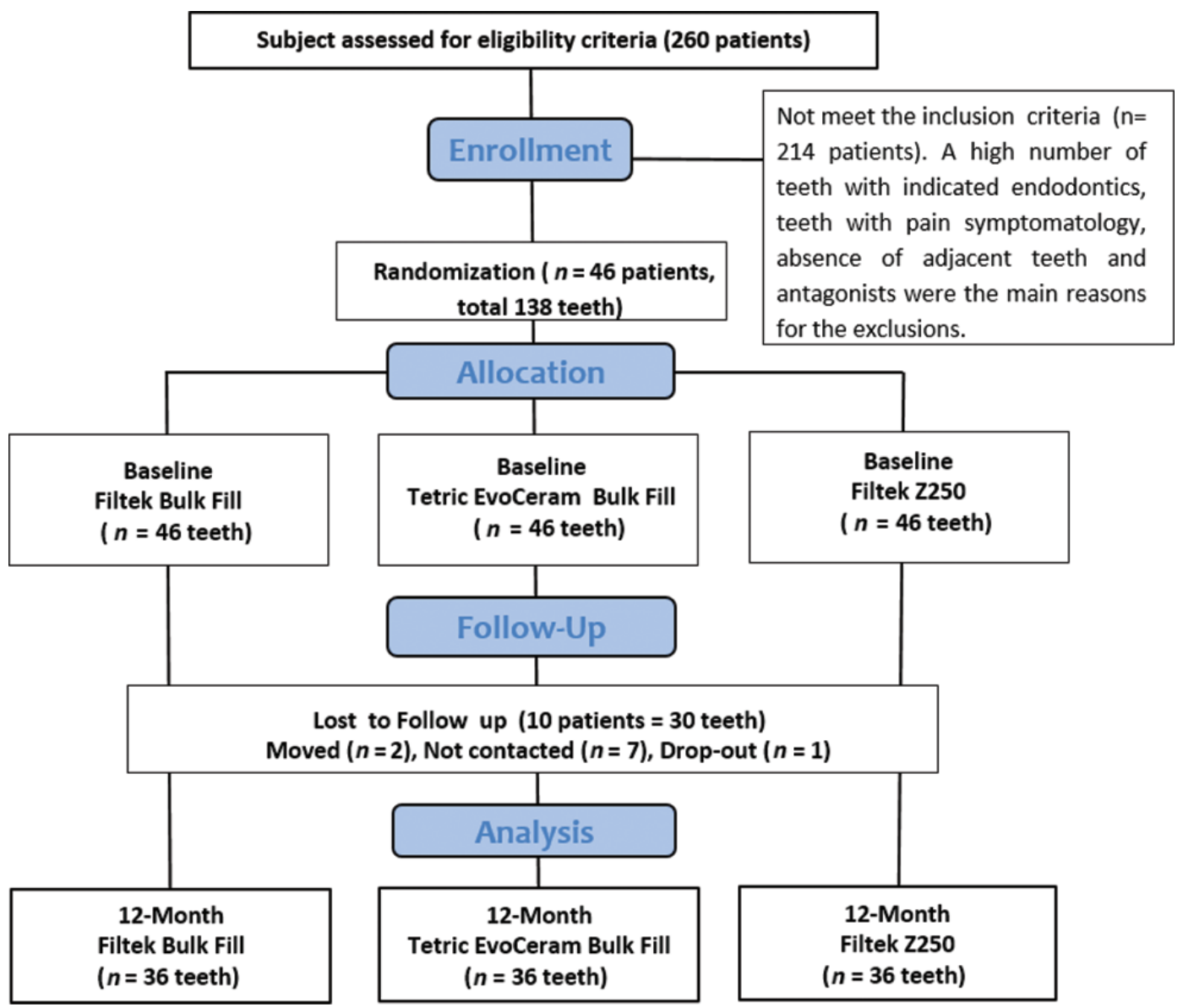

Fig. 1 Flow diagram of the study (Consolidated Standards of Reporting Trials [CONSORT] 2010).

Table 1 Composition, application, manufacturer, and batch number of each material used

\begin{tabular}{|c|c|c|c|}
\hline Material & Composition & Application step & $\begin{array}{l}\text { Manufacturer/batch } \\
\text { number }\end{array}$ \\
\hline $\begin{array}{l}\text { Clearfil SE } \\
\text { bond (SEB) }\end{array}$ & $\begin{array}{l}\text { Primer: HEMA, 10-MDP, 10-Methacryloyloxydecyl } \\
\text { dihydrogen phosphate, hydrophilic aliphatic dimeth- } \\
\text { acrylate, colloidal silica, dl-camphorquinone, water, } \\
\text { accelerators, dyes, (pH } \approx \text { idyl methacrylate, HEMA, } \\
10 \text { MDP-methacryloyloxydecyl dihydrogen phosphate, } \\
\text { hydrophobic aliphatic dimethacrylate, colloidal silica, } \\
\text { camphorquinone }\end{array}$ & $\begin{array}{l}\text { Primer: Active application } \\
\text { for } 20 \text { seconds air dried } \\
\text { for } 5 \text { seconds for solvent } \\
\text { evaporation. } \\
\text { Bond: active application, air } \\
\text { dried for solvent evaporation, } \\
\text { and light cured for } 10 \text { second }\end{array}$ & $\begin{array}{l}\text { Kuraray Medical, Inc.; } \\
\text { Tokyo, Japan } \\
(01245 A) \\
(01882 A)\end{array}$ \\
\hline $\begin{array}{l}\text { Tetric EvoCeram } \\
\text { Bulk Fill (TBF) }\end{array}$ & $\begin{array}{l}\text { Organic matrix: dimethacrylates (Bis-GMA, Bis- } \\
\text { EMA, UDMA). } \\
\text { Fillers: barium glass, ytterbium trifluoride, mixed } \\
\text { oxide, silica } \\
\text { Nanohybrid, } 79-81 \% \text { weight and } 60-61 \% \text { volume } \\
\text { (17\% prepolymers) }\end{array}$ & $\begin{array}{l}\text { Increment up to } 4 \mathrm{~mm} \text { and } \\
\text { light cured for } 10 \text { seconds } \\
\text { each side }^{\mathrm{a}}\end{array}$ & $\begin{array}{l}\text { Ivoclar Vivadent; Schaan, } \\
\text { Liechtenstein, GE } \\
\text { (T23727) }\end{array}$ \\
\hline $\begin{array}{l}\text { Filtek bulk } \\
\text { fill (FBF) }\end{array}$ & $\begin{array}{l}\text { Organic matrix: UDMA, AFM, AUDMA, DDDMA } \\
\text { 1,12-dodecanediol dimethacrylate } \\
\text { Fillers: zirconia-silica, ytterbium trifluoride. } \\
\text { Nanoparticle, } 76.5 \% \text { weight and } 58.4 \% \text { volume }\end{array}$ & $\begin{array}{l}\text { Increment up to } 5 \mathrm{~mm} \text {, light } \\
\text { cured for } 10 \text { seconds each } \\
\text { side: occlusal, buccal and } \\
\text { lingual }^{\mathrm{a}}\end{array}$ & $\begin{array}{l}\text { 3M ESPE; St. Paul, } \\
\text { Minnesota, United States } \\
\text { (N633573) }\end{array}$ \\
\hline $\begin{array}{l}\text { Filtek Z250 } \\
\text { XT (Z250) } \\
\text { (control group) }\end{array}$ & $\begin{array}{l}\text { Organic matrix: Bis-GMA, UDMA and Bis-EMA. } \\
\text { Fillers: zirconia-silica. } \\
\text { Microhybrid, } 82 \% \text { weight and } 60 \% \text { volume }\end{array}$ & $\begin{array}{l}\text { Incremental technique. A } \\
\text { 2-mm increment was applied } \\
\text { and light cured for } 20 \text { seconds }\end{array}$ & $\begin{array}{l}\text { 3M ESPE; St. Paul, } \\
\text { Minnesota, United States } \\
\text { (228214) }\end{array}$ \\
\hline
\end{tabular}

Abbreviations: 10-MDP, 10-methacryloyloxydecyldihydrogenphosphate; AFM, addition fragmentation monomers; AUDMA, aromatic urethane dimethacrylate; Bis-EMA, bisphenol A polyethyleneglycoldiether-dimethacrylate; Bis-GMA, bisphenol A-diglycidylether dimethacrylate; DDDMA, 1,12-dodecanediol dimethacrylate; HEMA, 2-hydroxyethyl methacrylate; UDMA, urethanedimethacrylate.

aClass-Il bulk fill restorations: after removal of the matrix band, the proximal regions were polymerized additionally on the buccal and lingual surfaces for 10 seconds. 


\section{Adherence and Recall Process}

To ensure adherence of the participants to the study, all volunteers underwent complete dental treatment and periodic follow-up. For the assessments, the volunteers were contacted by telephone, WhatsApp message, Facebook, and e-mail. Four attempts, including visits to the schools, were made to contact a volunteer before he/she was considered a "loss."

\section{Clinical Procedure}

Conservative cavity preparation was performed with a high-speed spherical diamond bur (no.: 1015-1017, KG Sorensen, Barueri, Brazil) under constant refrigeration. Intermittent rotary instrument contact with tooth limited to the removal of compromised enamel. The cavity outline was restricted to the removal of carious tissue with a manual instrument and spherical carbide bur at low speed. In the removal of defective restorations, the friable enamel and remnant carious tissue were removed in the same way. Anesthesia was applied if necessary to improve patient comfort.

All teeth were restored using a rubber dam. The selfetch bonding agent (Clearfil SE Bond, SEB, Kuraray, Tokyo, Japan) was applied with previous selective enamel etching with $37 \%$ phosphoric acid for 30 seconds. In deep cavities ( $\geq 4 \mathrm{~mm}$ ), dentine hardness was considered to define the need for lining with a modified glass ionomer cement (Vitrebond, 3M ESPE, St. Paul, Minnesota, United States). In the presence of harder reparative dentin, no lining was used. These materials were inserted following the manufacturer's instructions (- Table 1). All photoactivation procedures were performed with a LED unit in the continuous mode at a light intensity of $1200 \mathrm{~mW} / \mathrm{cm}^{2}$ (Radii-cal, SDI,
Victoria, Australia). A precontoured sectional matrix system (Unimatrix, TDV, Pomerode, Santa Catarina, Brazil) and wooden wedges (TDV, Pomerode, Santa Catarina, Brazil) were used to restore class-II cavities. The resin composites were applied and light-cured following the manufacturer's instructions (-Table 1).

At the end of each restoration, occlusal contacts were checked (AccuFilm, Parkell, New York, United States), and fine-grit dental burs were used for occlusal adjustments. The proximal contact and cervical adaptation were checked with dental floss and adjusted with aluminum oxide-impregnated strips (Sof-Lex Finishing and Polishing System, 3M ESPE, St. Paul, Minnesota, United States). After 24 hours, the restorations were finished with fine and extra-fine-grit diamond burs (KG Sorensen). Silicon polishers with diamond particles (Astropol, Ivoclar Vivadent, Schaan, Liechtenstein) in a decreasing sequence of abrasiveness and silicon carbide brush (Astrobrush, Ivoclar Vivadent) were also used at low speed under constant water-cooling using intermittent movements.

\section{Calibration and Data Collection}

After 1 week (baseline), the restorations were evaluated after 12 months by three dentists who did not participate in the restorative procedure and were blind regarding treatment allocation. The evaluators were calibrated before the study by a joint examination of 20 direct resin composite restorations from other volunteers who did not participate in the clinical trial (Cohen's $K=0.84) .{ }^{34}$ The restorations were clinically assessed according to the modified USPHS criteria (-Table 2 ) and FDI criteria (-Table 3 ) considering esthetic, functional, and biological features. ${ }^{35}$

Table 2 Modified United States Public Health Service Evaluation (USPHS) criteria

\begin{tabular}{|c|c|c|}
\hline Category & Score & Definition \\
\hline \multirow[t]{3}{*}{ Anatomic form } & Alpha & Restoration continuous with existing anatomic form \\
\hline & Bravo & $\begin{array}{l}\text { Restoration discontinuous with existing anatomic form, but loss of material is not sufficient } \\
\text { to expose the dentin or base }\end{array}$ \\
\hline & Charlie & Loss of material sufficient to expose the dentin or base \\
\hline \multirow[t]{3}{*}{ Marginal adaptation } & Alpha & $\begin{array}{l}\text { Restoration completely adapted to the tooth. No visible gap. No explorer catch at the mar- } \\
\text { gins or in any direction }\end{array}$ \\
\hline & Bravo & Explorer catch. There is no visible evidence of a gap into which the explorer could penetrate \\
\hline & Charlie & Explorer penetrates into a deep gap that exposes dentin or base \\
\hline \multirow[t]{3}{*}{ Marginal discoloration } & Alpha & No discoloration along the cavosuperficial margin \\
\hline & Bravo & $<50 \%$ of the cavosuperficial margin affected by stain \\
\hline & Charlie & $>50 \%$ of the cavosuperficial margin affected by stain \\
\hline \multirow[t]{3}{*}{ Color match } & Alpha & Restoration with color and translucency similar to those of the adjacent dental structure \\
\hline & Bravo & Change in color and translucency within an acceptable standard \\
\hline & Charlie & Change in color outside the acceptable standard \\
\hline \multirow[t]{3}{*}{ Surface roughness } & Alpha & Restoration surface is smooth \\
\hline & Bravo & Restoration surface is slightly rough or has scratches, but can be refinished \\
\hline & Charlie & Surface deeply rough, with irregular scratches; cannot be refinished \\
\hline \multirow[t]{2}{*}{ Recurrent caries } & Alpha & Absent \\
\hline & Charlie & Present \\
\hline \multirow[t]{2}{*}{ Postoperative sensitivity } & Alpha & Absent \\
\hline & Charlie & Present \\
\hline
\end{tabular}




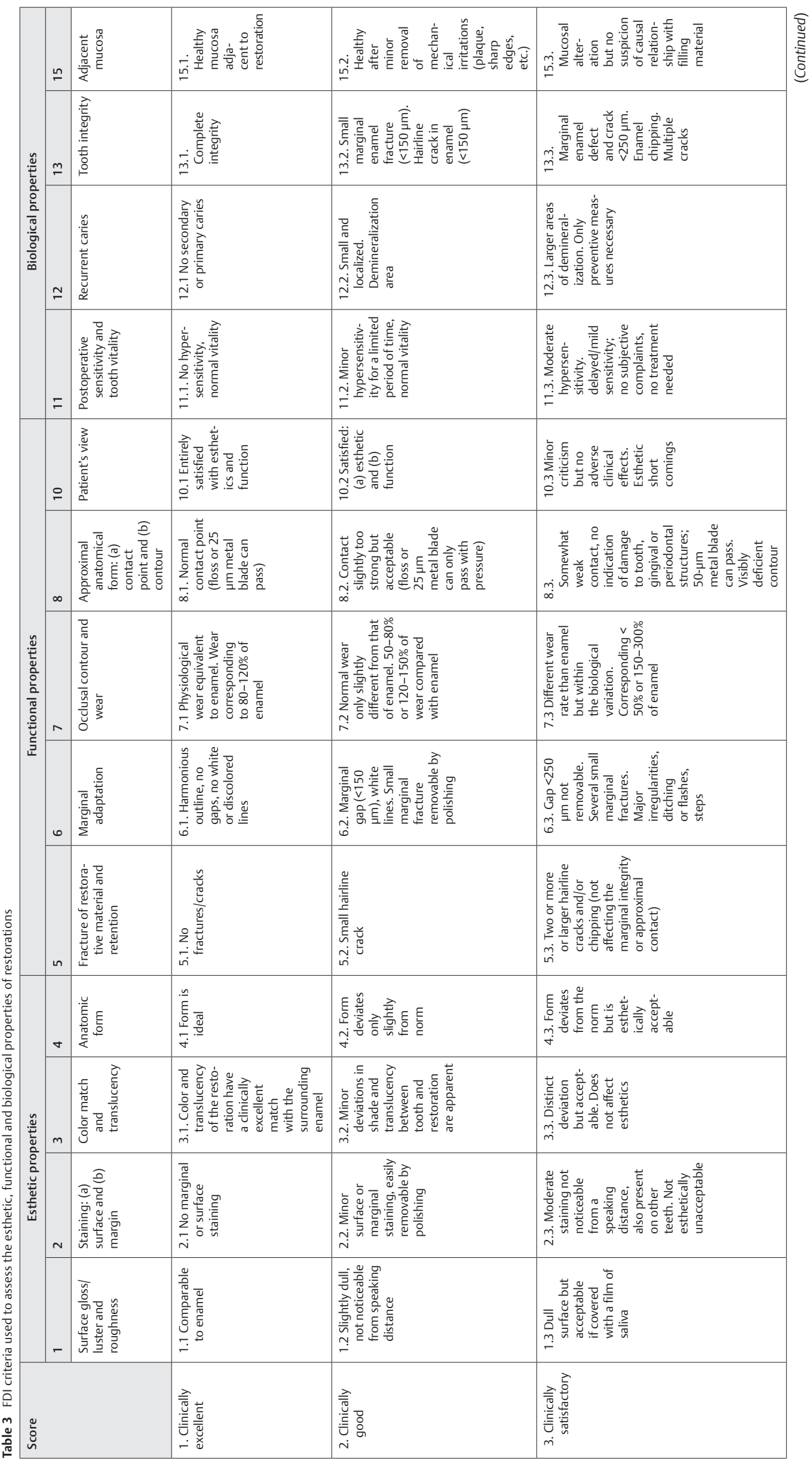




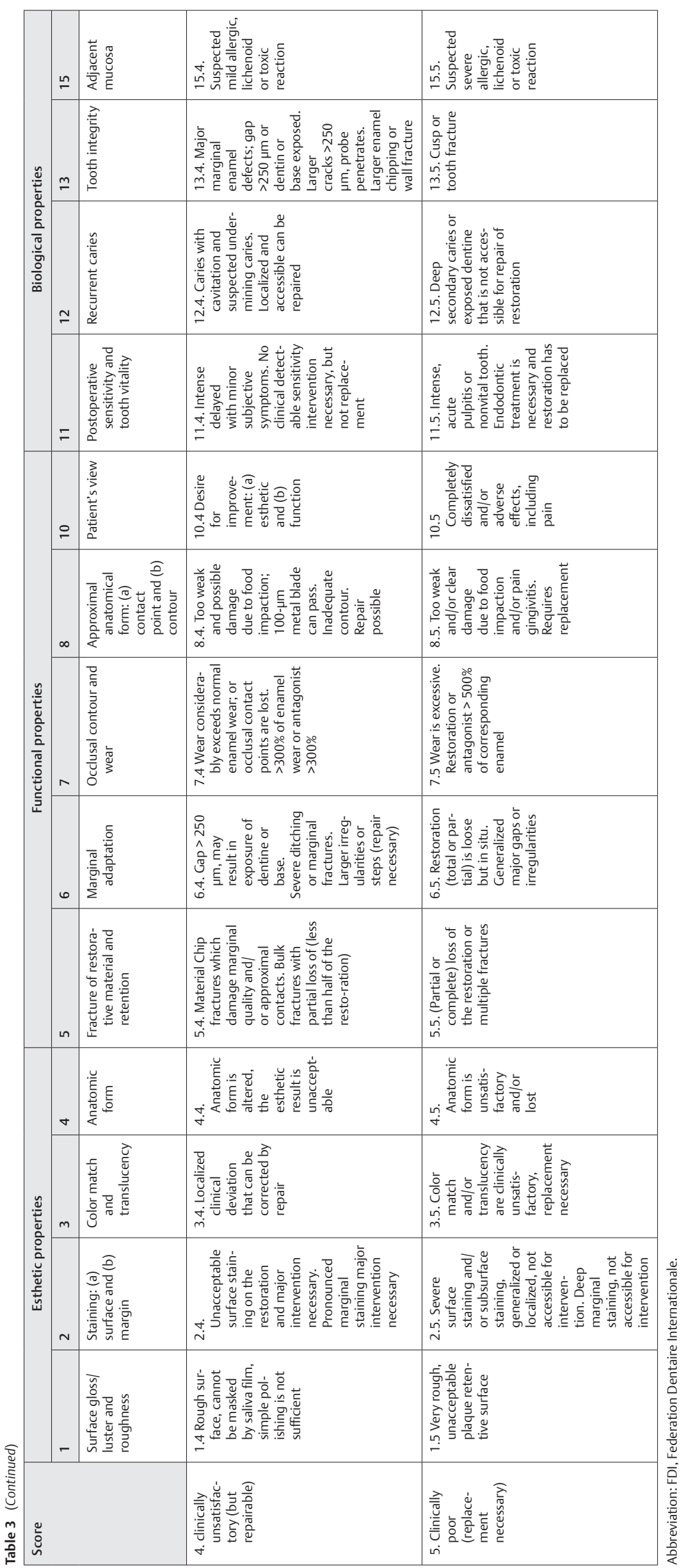


For each volunteer, one tooth was evaluated at a time by all three evaluators. In the case of score disagreement, a consensus decision was obtained, reexamining the patient when necessary. ${ }^{36}$

For the modified USPHS criteria, failure was only considered when a Charlie score was attributed. For the FDI criteria, scores 1, 2, and 3 are clinically excellent, good, and satisfactory. Score 4 was clinically unsatisfactory but repairable, while in the case of score 5, the restoration was considered clinically poor/failure and should be replaced.

The modified USPHS and FDI criteria were compared in each group at the different observation times considering the common categories: marginal adaptation, color match/ color match and translucency, marginal discoloration/ staining (margin), anatomic form, surface roughness, and surface gloss/luster and roughness, postoperative sensitivity, and recurrent caries. The restorations were categorized by relating the USPHS and FDI criteria, where alpha corresponds to scores 1 and 2 (success); bravo corresponds to score 3 (clinically acceptable), and; charlie corresponds to scores 4 (clinically unsatisfactory but repairable) and 5 (clinically poor/failure). ${ }^{26}$

The Eq. $(- \text { year })^{z}=(1-x)$ was used to calculate the annual failure rate (AFR) of the restorations. The mean AFR is expressed by " $y$ " and " $x$ " the total failure rate at " $z$ " years. ${ }^{37}$

\section{Data Analysis}

The Statistical Package for the Social Sciences (SPSS, version 23) was used for statistical analysis. Statistical measures were calculated to describe the distribution of the data. Fisher's exact test and Pearson's Chi-squared test were used to evaluating the homogeneity of distribution of the clinical characteristics of the samples. Friedman's test was applied to evaluate the resin composites' difference at each time point and differences between time points for each resin composite. The results obtained for the USPHS and FDI criteria at the different observation times were compared using the Wilcoxon test. A level of significance of 0.05 was adopted for all tests.

\section{Results}

Twenty-two (47.8\%) of the 46 adolescents were boys, and 24 (52.2\%) were girls. The initial decayed, missing and filled teeth (DMF) index of the 46 volunteers was 9.12. However, the caries component made the most substantial contribution to this value (87\%), followed by the missing (11\%) and filled (2\%) components.

The clinical characteristics of the restored cavities are shown in - Table 4. The distribution of the variables was homogenous in the three groups for the type of tooth restored, cavity classification, cavity width (buccal-lingual

Table 4 Clinical characteristics of the different groups studied

\begin{tabular}{|c|c|c|c|c|c|c|c|c|c|c|}
\hline \multirow[t]{3}{*}{ Characteristic } & \multicolumn{6}{|c|}{ Group } & \multirow{2}{*}{\multicolumn{2}{|c|}{ Total }} & \multirow{2}{*}{\multicolumn{2}{|c|}{$p$-Value ${ }^{a}$}} \\
\hline & \multicolumn{2}{|c|}{$\mathrm{Z} 250$} & \multicolumn{2}{|c|}{ TBF } & \multicolumn{2}{|c|}{ FBF } & & & & \\
\hline & Baseline & $12 \mathrm{mo}$ & Baseline & $12 \mathrm{mo}$ & Baseline & $12 \mathrm{mo}$ & Baseline & $12 \mathrm{mo}$ & Baseline & $12 \mathrm{mo}$ \\
\hline \multicolumn{11}{|l|}{ Tooth } \\
\hline $\begin{array}{l}\text { Upper } \\
\text { premolar }\end{array}$ & 11 & 10 & 9 & 7 & 12 & 9 & 32 & 26 & \multirow[t]{4}{*}{$p^{1}=0.987$} & \multirow[t]{4}{*}{$p^{(1)}=0.600$} \\
\hline $\begin{array}{l}\text { Lower } \\
\text { premolar }\end{array}$ & 4 & 3 & 5 & 5 & 5 & 5 & 14 & 13 & & \\
\hline Upper molar & 23 & 17 & 22 & 16 & 21 & 17 & 66 & 50 & & \\
\hline Lower molar & 8 & 6 & 10 & 8 & 8 & 5 & 26 & 19 & & \\
\hline \multicolumn{11}{|c|}{ Cavity classification } \\
\hline Class I & 36 & 29 & 34 & 27 & 31 & 25 & 101 & 81 & \multirow[t]{2}{*}{$p^{2}=0.736$} & \multirow[t]{2}{*}{$p^{(2)}=0.553$} \\
\hline Class II & 10 & 7 & 12 & 9 & 15 & 11 & 37 & 27 & & \\
\hline \multicolumn{11}{|l|}{ Cavity width } \\
\hline$<1 / 3$ & 24 & 13 & 19 & 8 & 21 & 11 & 64 & 32 & \multirow[t]{2}{*}{$p^{2}=0.575$} & \multirow[t]{2}{*}{$p^{(2)}=0.430$} \\
\hline$>1 / 3$ & 22 & 23 & 27 & 28 & 25 & 25 & 74 & 76 & & \\
\hline \multicolumn{11}{|l|}{ Cavity depth } \\
\hline Medium & 23 & 17 & 13 & 7 & 12 & 9 & 48 & 33 & \multirow[t]{2}{*}{$p^{2}=0.029$} & \multirow[t]{2}{*}{$p^{(2)}=0.028$} \\
\hline Deep & 23 & 19 & 33 & 29 & 34 & 26 & 90 & 74 & & \\
\hline \multicolumn{11}{|l|}{ Pulp protection } \\
\hline $\begin{array}{l}\text { Bonding } \\
\text { agent }\end{array}$ & 30 & 22 & 23 & 17 & 27 & 22 & 80 & 62 & \multirow[t]{2}{*}{$p^{2}=0.333$} & \multirow[t]{2}{*}{$p^{(2)}=0.309$} \\
\hline $\begin{array}{l}\text { Glass iono- } \\
\text { mer cement }\end{array}$ & 16 & 14 & 23 & 19 & 19 & 14 & 58 & 46 & & \\
\hline
\end{tabular}


isthmus), and type of pulp protection ( $p>0.05)$. However, regarding cavity depth, the number of deep cavities was higher for the bulk-fill resin composites.

The results of the restorations, clinical evaluation according to the modified USPHS and FDI criteria are shown in - Tables 5 and 6. Among the 138 restorations performed in 46 patients, 108 were evaluated after 12 months in 36 patients (recall rate of $78.3 \%$ ). However, the absence of 10 patients $(21.7 \%)$ did not characterize the loss of individual groups due to the split-mouth design.

Significant differences between observation times were observed for "marginal adaptation" and "surface roughness” (-Table 5). For marginal adaptation, differences were observed between time points $(p<0.001)$ for all resin composites tested, with a reduction in the number of alpha ratings. No significant differences were observed between groups. However, at 12 months, one failure (Charlie) was observed for the Tetric EvoCeram bulk fill (TBF) group.

Surface roughness differed significantly between the TBF group and the other groups studied. A significant increase in roughness was observed in the Z250 and Filtek bulk fill (FBF) groups after 12 months ( $p<0.001$ and 0.003 , respectively). A higher percentage of alpha scores was obtained for the TBF resin at baseline (95.7\%) and after 12 months (91.7\%), with no significant difference between time points $(p=0.383)$.
Evaluation of anatomic form revealed no significant differences between groups or times $(p=1.0)$. However, one restoration of the TBF group was scored bravo at baseline and after 12 months.

Two volunteers in the $\mathrm{Z} 250$ group reported postoperative sensitivity at baseline. Clinical follow-up showed that sensitivity was transient. After 12 months, these restorations received an alpha score after clinical examination, vitality testing, and radiographic examination.

Among the esthetic properties evaluated by the FDI criteria (-Table 6), significant differences between groups at baseline and after 12 months were observed for the surface gloss/luster and roughness category $(p<0.001)$, with score 3 being attributed at baseline (2.2\%) and score 2 after 12 months (5.6\%) in the Z250 group. A similar trend was found for the other resin composites at baseline and 12 months, with more than $90 \%$ of the restorations receiving scores 1 and 2 (excellent/good) at the different time points. For the anatomic form category, significant differences were observed between the TBF group and the other resins at baseline ( $p<0.001)$, with $15.2 \%$ of the restorations receiving score 2 and $6.5 \%$ receiving score 3 . At 12 months, $50 \%$ of the TBF restorations received score 2 .

None of the functional properties differed significantly among groups. When observation times were compared, significant differences were observed for all three groups

Table 5 Results of clinical evaluation of the restorations according to the modified USPHS criteria

\begin{tabular}{|c|c|c|c|c|c|c|c|c|c|c|c|c|c|}
\hline \multirow[t]{3}{*}{ Category } & \multirow[t]{3}{*}{ Score } & \multicolumn{6}{|c|}{ Baseline $(n=46)$} & \multicolumn{6}{|c|}{12 months $(n=36)$} \\
\hline & & \multicolumn{2}{|c|}{$\mathrm{Z250}$} & \multicolumn{2}{|c|}{ TBF } & \multicolumn{2}{|c|}{$\mathrm{FBF}$} & \multicolumn{2}{|c|}{$\mathrm{Z250}$} & \multicolumn{2}{|c|}{ TBF } & \multicolumn{2}{|r|}{ FBF } \\
\hline & & $n$ & $\%$ & $n$ & $\%$ & $n$ & $\%$ & $n$ & $\%$ & $n$ & $\%$ & $n$ & $\%$ \\
\hline \multirow{3}{*}{$\begin{array}{l}\text { Marginal } \\
\text { adaptation }\end{array}$} & A & $39^{a}$ & 84.8 & $41^{\mathrm{a}}$ & 89.1 & $39^{a}$ & 84.8 & $9^{\mathrm{b}}$ & 25 & $16^{c}$ & 44.4 & $16^{c}$ & 44.4 \\
\hline & B & $7^{\mathrm{a}}$ & 15.2 & $5^{a}$ & 10.9 & $7^{\mathrm{a}}$ & 15.2 & $27^{b}$ & 75 & $19^{c}$ & 52.8 & $20^{c}$ & 55.6 \\
\hline & C & - & - & - & - & - & - & - & - & 1 & 2.8 & - & - \\
\hline \multirow[t]{3}{*}{ Color match } & A & 46 & 100 & 46 & 100 & 46 & 100 & 36 & 100 & 36 & 100 & 36 & 100 \\
\hline & B & - & - & - & - & - & - & - & - & - & - & - & - \\
\hline & C & - & - & - & - & - & - & - & - & - & - & - & - \\
\hline \multirow{3}{*}{$\begin{array}{l}\text { Marginal } \\
\text { discoloration }\end{array}$} & $A$ & 46 & 100 & 46 & 100 & 46 & 100 & 34 & 94.4 & 35 & 97.2 & 33 & 91.7 \\
\hline & $\mathrm{B}$ & - & - & - & - & - & - & 2 & 5.6 & 1 & 2.8 & 3 & 8.3 \\
\hline & C & - & - & - & - & - & - & - & - & - & - & - & - \\
\hline \multirow[t]{3}{*}{ Anatomic form } & $A$ & 46 & 100 & 45 & 97.8 & 46 & 100 & 36 & 100 & 35 & 97.2 & 36 & 100 \\
\hline & B & - & - & 1 & 2.2 & - & - & - & - & 1 & 2.8 & - & - \\
\hline & $C$ & - & - & - & - & - & - & - & - & - & - & - & - \\
\hline \multirow{3}{*}{$\begin{array}{l}\text { Surface } \\
\text { roughness }\end{array}$} & A & $29^{A, a}$ & 63 & $44^{\mathrm{B}}$ & 95.7 & $32^{\mathrm{A}, \mathrm{a}}$ & 69.6 & $7^{A, b}$ & 19.4 & $33^{B}$ & 91.7 & $11^{\mathrm{Ab}}$ & 30.6 \\
\hline & B & 17 & 37 & 2 & 4.3 & 14 & 30.4 & 29 & 80.6 & 3 & 8.3 & 25 & 69.4 \\
\hline & $C$ & - & - & - & - & - & - & - & - & - & - & - & - \\
\hline \multirow{2}{*}{$\begin{array}{l}\text { Postoperative } \\
\text { sensitivity }\end{array}$} & A & 44 & 95.7 & 46 & 100 & 46 & 100 & 36 & 100 & 36 & 100 & 36 & 100 \\
\hline & $C$ & 2 & 4.3 & - & - & - & - & - & - & - & - & - & - \\
\hline \multirow[t]{2}{*}{ Recurrent caries } & $A$ & 46 & 100 & 46 & 100 & 46 & 100 & 36 & 100 & 36 & 100 & 36 & 100 \\
\hline & C & - & - & - & - & - & - & - & - & - & - & - & - \\
\hline
\end{tabular}

Abbreviations: FBF, Filtek bulk fill; TBF, Tetric EvoCeram bulk fill; USPHS, the United States Public Health Service.

Note: Different superscript letters indicate significant differences between groups by the Friedman's test (lower case letters [footnotes]: differences between times of observation; upper case letters [footnotes]: differences between groups). 
Full-body Bulk-fill Resin Composite 12-Month Follow-up Durão et al. 187

Table 6 Results of clinical evaluation according to the FDI criteria

\begin{tabular}{|c|c|c|c|c|c|c|c|c|c|c|c|c|c|c|}
\hline \multirow{3}{*}{\multicolumn{2}{|c|}{ Category }} & \multirow[t]{3}{*}{ Score } & \multicolumn{6}{|c|}{ Baseline $(n=46)$} & \multicolumn{6}{|c|}{12 months $(n=36)$} \\
\hline & & & \multicolumn{2}{|c|}{$\mathrm{Z250}$} & \multicolumn{2}{|c|}{ TBF } & \multicolumn{2}{|c|}{ FBF } & \multicolumn{2}{|c|}{ Z250 } & \multicolumn{2}{|c|}{ TBF } & \multicolumn{2}{|r|}{ FBF } \\
\hline & & & $n$ & $\%$ & $n$ & $\%$ & $n$ & $\%$ & $n$ & $\%$ & $n$ & $\%$ & $n$ & $\%$ \\
\hline \multirow{25}{*}{$\begin{array}{l}\text { Esthetic } \\
\text { properties }\end{array}$} & \multirow{5}{*}{$\begin{array}{l}\text { Surface gloss/ } \\
\text { luster and } \\
\text { roughness }\end{array}$} & 1 & 35 & $76.1^{\text {Aa }}$ & 46 & $100^{\mathrm{B}}$ & 43 & $93.5^{\mathrm{B}}$ & 16 & $(44.4)^{\mathrm{Ab}}$ & 34 & $94.4^{\mathrm{B}}$ & 26 & $72.2^{c}$ \\
\hline & & 2 & 10 & 21.7 & - & - & 3 & 6.5 & 18 & $(50.0)$ & 2 & 5.6 & 10 & 27.8 \\
\hline & & 3 & 1 & 2.2 & - & - & - & - & 2 & 5.6 & - & - & - & - \\
\hline & & 4 & - & - & - & - & - & - & - & - & - & - & - & - \\
\hline & & 5 & - & - & - & - & - & - & - & - & - & - & - & - \\
\hline & \multirow{5}{*}{$\begin{array}{l}\text { Staining: (a) } \\
\text { surface }\end{array}$} & 1 & 46 & 100 & 46 & 100 & 46 & 100 & 34 & 94.4 & 35 & 100 & 35 & 100 \\
\hline & & 2 & - & - & - & - & - & - & 2 & 5.6 & 1 & 2.8 & 1 & 2.8 \\
\hline & & 3 & - & - & - & - & - & - & - & - & - & - & - & - \\
\hline & & 4 & - & - & - & - & - & - & - & - & - & - & - & - \\
\hline & & 5 & - & - & - & - & - & - & - & - & - & - & - & - \\
\hline & Staining: (b) & 1 & 46 & 100 & 46 & 100 & 46 & 100 & 34 & 94.4 & 35 & 100 & 34 & 94.4 \\
\hline & margin & 2 & - & - & - & - & - & - & 2 & 5.6 & 1 & 2.8 & 2 & 5.6 \\
\hline & & 3 & - & - & - & - & - & - & - & - & - & - & - & - \\
\hline & & 4 & - & - & - & - & - & - & - & - & - & - & - & - \\
\hline & & 5 & - & - & - & - & - & - & - & - & - & - & - & - \\
\hline & Color match and & 1 & 46 & 100 & 46 & 100 & 46 & 100 & 36 & 100 & 36 & 100 & 36 & 100 \\
\hline & & 2 & - & - & - & - & - & - & - & - & - & - & - & - \\
\hline & & 3 & - & - & - & - & - & - & - & - & - & - & - & - \\
\hline & & 4 & - & - & - & - & - & - & - & - & - & - & - & - \\
\hline & & 5 & - & - & - & - & - & - & - & - & - & - & - & - \\
\hline & Anatomic form & 1 & 45 & $97.8^{\mathrm{A}}$ & 36 & $78.3^{\mathrm{B}}$ & 46 & $100^{A}$ & 36 & $(100)^{A}$ & 17 & $47.2^{\mathrm{B}}$ & 36 & $100^{A}$ \\
\hline & & 2 & - & - & 7 & 15.2 & - & - & - & - & 18 & 50.0 & - & - \\
\hline & & 3 & - & - & 3 & 6.5 & - & - & - & - & 1 & 2.2 & - & - \\
\hline & & 4 & - & - & - & - & - & - & - & - & - & - & - & - \\
\hline & & 5 & - & - & - & - & - & - & - & - & - & - & - & - \\
\hline Functional & Fracture and & 1 & 46 & 100 & 45 & 97.8 & 36 & 100 & 36 & 100 & 35 & 97.2 & 36 & 100 \\
\hline & retention & 2 & - & - & 1 & 2.2 & - & - & - & - & 1 & 2.8 & - & - \\
\hline & & 3 & - & - & - & - & - & - & - & - & - & - & - & - \\
\hline & & 4 & - & - & - & - & - & - & - & - & - & - & - & - \\
\hline & & 5 & - & - & - & - & - & - & - & - & - & - & - & - \\
\hline & Marginal & 1 & 38 & $82.6^{a}$ & 40 & $87^{a}$ & 39 & $84.8^{a}$ & 10 & $27.8^{\mathrm{b}}$ & 17 & $47.2^{\mathrm{b}}$ & 14 & $38.9^{b}$ \\
\hline & adaptation & 2 & 8 & 17.4 & 6 & 13 & 7 & 15.2 & 26 & 72.2 & 17 & 47.2 & 20 & 55.6 \\
\hline & & 3 & - & - & - & - & - & - & - & - & 1 & 2.8 & 2 & 5.6 \\
\hline & & 4 & - & - & - & - & - & - & - & - & 1 & 2.8 & - & - \\
\hline & & 5 & - & - & - & - & - & - & - & - & - & - & - & - \\
\hline & Occlusal contour & 1 & 46 & 100 & 46 & 100 & 46 & 100 & 36 & 100 & 36 & $(100)$ & 36 & $(100)$ \\
\hline & and wear & 2 & - & - & - & - & - & - & - & - & - & - & - & - \\
\hline & & 3 & - & - & - & - & - & - & - & - & - & - & - & - \\
\hline & & 4 & - & - & - & - & - & - & - & - & - & - & - & - \\
\hline & & 5 & - & - & - & - & - & - & - & - & - & - & - & - \\
\hline & Approximal & 1 & 10 & 100 & 12 & 100 & 15 & 100 & 8 & 1,000 & 10 & 100 & 12 & 100 \\
\hline & anatomic form & 2 & - & - & - & - & - & - & - & - & - & - & - & - \\
\hline & & 3 & - & - & - & - & - & - & - & - & - & - & - & - \\
\hline & & 4 & - & - & - & - & - & - & - & - & - & - & - & - \\
\hline & & 5 & - & - & - & - & - & - & - & - & - & - & - & - \\
\hline & & 1 & 10 & 100 & 12 & 100 & 15 & 100 & 8 & 1,000 & 10 & 100 & 12 & 100 \\
\hline & anatomic form & 2 & - & - & - & - & - & - & - & - & - & - & - & - \\
\hline & & 3 & - & - & - & - & - & - & - & - & - & - & - & - \\
\hline & & 4 & - & - & - & - & - & - & - & - & - & - & - & - \\
\hline & & 5 & - & - & - & - & - & - & - & - & - & - & - & - \\
\hline & Patient's view & 1 & 46 & $100^{\mathrm{a}}$ & 46 & $100^{\mathrm{a}}$ & 45 & $97.8^{\mathrm{a}}$ & 17 & $47.2^{\mathrm{b}}$ & 18 & $50^{\mathrm{b}}$ & 16 & $44.4^{b}$ \\
\hline & & 2 & - & - & - & - & 1 & 2.2 & 19 & 52.8 & 18 & 50 & 18 & 50 \\
\hline & & 3 & - & - & - & - & - & - & - & - & - & - & 2 & 5.6 \\
\hline & & 4 & - & - & - & - & - & - & - & - & - & - & - & - \\
\hline & & 5 & - & - & - & - & - & - & - & - & - & - & - & - \\
\hline
\end{tabular}


Table 6 (Continued)

\begin{tabular}{|c|c|c|c|c|c|c|c|c|c|c|c|c|c|c|}
\hline \multirow{3}{*}{\multicolumn{2}{|c|}{ Category }} & \multirow[t]{3}{*}{ Score } & \multicolumn{6}{|c|}{ Baseline $(n=46)$} & \multicolumn{6}{|c|}{12 months $(n=36)$} \\
\hline & & & \multicolumn{2}{|c|}{$\mathrm{Z250}$} & \multicolumn{2}{|c|}{ TBF } & \multicolumn{2}{|c|}{ FBF } & \multicolumn{2}{|c|}{$\mathrm{Z} 250$} & \multicolumn{2}{|c|}{ TBF } & \multicolumn{2}{|r|}{ FBF } \\
\hline & & & $n$ & $\%$ & $n$ & $\%$ & $n$ & $\%$ & $n$ & $\%$ & $n$ & $\%$ & $n$ & $\%$ \\
\hline \multirow{20}{*}{$\begin{array}{l}\text { Biological } \\
\text { properties }\end{array}$} & \multirow{5}{*}{$\begin{array}{l}\text { Postoperative } \\
\text { (hyper) sensitivity } \\
\text { and tooth vitality }\end{array}$} & 1 & 44 & 95.7 & 46 & 100 & 46 & 100 & 36 & 100 & 36 & 100 & 36 & 100 \\
\hline & & 2 & 2 & 4.3 & - & - & - & - & - & - & - & - & - & - \\
\hline & & 3 & - & - & - & - & - & - & - & - & - & - & - & - \\
\hline & & 4 & - & - & - & - & - & - & - & - & - & - & - & - \\
\hline & & 5 & - & - & - & - & - & - & - & - & - & - & - & - \\
\hline & \multirow[t]{5}{*}{ Recurrent caries } & 1 & 46 & 100 & 46 & 100 & 46 & 100 & 36 & 100 & 36 & 100 & 36 & 100 \\
\hline & & 2 & - & - & - & - & - & - & - & - & - & - & - & - \\
\hline & & 3 & - & - & - & - & - & - & - & - & - & - & - & - \\
\hline & & 4 & - & - & - & - & - & - & - & - & - & - & - & - \\
\hline & & 5 & - & - & - & - & - & - & - & - & - & - & - & - \\
\hline & \multirow[t]{5}{*}{ Tooth integrity } & 1 & 46 & 100 & 46 & 100 & 46 & 100 & 36 & 100 & 36 & 100 & 36 & 100 \\
\hline & & 2 & - & - & - & - & - & - & - & - & - & - & - & - \\
\hline & & 3 & - & - & - & - & - & - & - & - & - & - & - & - \\
\hline & & 4 & - & - & - & - & - & - & - & - & - & - & - & - \\
\hline & & 5 & - & - & - & - & - & - & - & - & - & - & - & - \\
\hline & \multirow[t]{5}{*}{ Adjacent mucosa } & 1 & 46 & 100 & 46 & 100 & 46 & 100 & 36 & 100 & 36 & 100 & 36 & 100 \\
\hline & & 2 & - & - & - & - & - & - & - & - & - & - & - & - \\
\hline & & 3 & - & - & - & - & - & - & - & - & - & - & - & - \\
\hline & & 4 & - & - & - & - & - & - & - & - & - & - & - & - \\
\hline & & 5 & - & - & - & - & - & - & - & - & - & - & - & - \\
\hline
\end{tabular}

Abbreviations: FBF, Filtek bulk fill; FDI, Federation Dentaire Internationale; TBF, Tetric EvoCeram bulk fill.

Note: Different superscript letters indicate significant differences between groups by the Friedman test (lower case letters [footnotes]: differences between times of observation; upper case letters [footnotes]: differences between groups).

$(p<0.001)$. Concerning proximal anatomic form (contact point and contour), 37 restorations were evaluated at baseline and 30 restorations after 12 months, and no differences were observed between groups or time points.

Regarding biological properties, no differences were observed between groups or observation times. Two of the 46 patients evaluated at baseline reported postoperative sensitivity in the restored teeth, attributing score 2 to the Filtek Z250 resin composite, which did not persist at 12 months, changing to score 1 .

The overall success rate in 12 months was $97.2 \%$. Failure was detected in one restoration (1\%) during the follow-up of the TBF group for the marginal adaptation category using either the USPHS or FDI criteria.

The Wilcoxon test for paired data compared the USPHS and FDI criteria. Among all comparisons, differences were only found for the surface roughness and surface gloss/luster and roughness and the marginal adaptation categories. - Table 7 shows statistically significant differences for the evaluation of surface roughness (modified USPHS) and surface gloss/luster and roughness (FDI) in the Z250 and FBF group at baseline and after 12 months. In general, for these groups, a higher percentage of acceptable scores was obtained by the USPHS criteria. For marginal adaptation, significant differences between the criteria were observed in all groups at 12 months of observation ( $\mathbf{- T a b l e ~} \mathbf{8})$. The percentage of the acceptable scores was significantly higher for the USPHS criteria.

\section{Discussion}

The first null hypothesis of this study was not rejected since no significant differences were found in the clinical performance of the materials tested. The overall success rate of the restorations after 12 months was $97.22 \%$ for both criteria. The resin composites inserted into 92 molars ( 73 class I and 19 class II) and 46 premolars ( 28 class I and 18 class II) that exhibited a similar clinical performance over the 12-month observation period. According to both the modified USPHS and FDI criteria, failure was only found for the TBF resin composite in the marginal adaptation category. A class-I restoration in an upper premolar (tooth 25) restored due to a primary carious lesion using only the bonding agent as the pulp protection. No failures were observed in the Z250 and FBF groups. Therefore, the AFR of the TBF group was $1.0 \%$ for the two criteria used.

These findings are in agreement with those reported by other 1-year clinical evaluation using the USPHS criteria. ${ }^{23,38,39}$ However, the studied populations' DMF index was not mentioned, and poor oral hygiene was considered an exclusion criterion. ${ }^{23,38}$ Bayraktar et al. (2017) ${ }^{23}$ analyzed 172 class-II restorations (recall rate of $86 \%, 43$ patients) and compared three bulk-fill resin composites (Tetric EvoCeram Bulk Fill, Sonic Fill, Filtek Bulk Fill Flow + Filtek P60) with a conventional resin composite (Clearfil photo posterior). The prepared cavities were isolated with cotton rolls, and 
Table 7 Comparison of the results for surface roughness (modified USPHS) and surface gloss/luster and roughness (FDI)

\begin{tabular}{|c|c|c|c|c|c|c|c|}
\hline \multirow[t]{3}{*}{ Evaluation } & \multirow[t]{3}{*}{ Group } & \multirow[t]{3}{*}{ Score ${ }^{a}$} & \multicolumn{4}{|c|}{ Criteria } & \multirow[t]{3}{*}{$p$-Value } \\
\hline & & & \multicolumn{2}{|c|}{ FDI } & \multicolumn{2}{|c|}{ USPHS } & \\
\hline & & & $n$ & $\%$ & $n$ & $\%$ & \\
\hline \multirow[t]{8}{*}{ Baseline $(n=46)$} & \multirow[t]{3}{*}{ Z250 } & Success & 45 & 97.8 & 29 & 63.0 & $<0.001$ \\
\hline & & Acceptable & 1 & 2.2 & 17 & 37.0 & \\
\hline & & Poor/failure & - & - & - & - & \\
\hline & \multirow[t]{3}{*}{ TBF } & Success & 46 & 100 & 44 & 95.7 & 0.500 \\
\hline & & Acceptable & - & - & 2 & 4.3 & \\
\hline & & Poor/failure & - & - & - & - & \\
\hline & \multirow[t]{3}{*}{ FBF } & Success & 46 & 100 & 32 & 69.6 & $<0.001$ \\
\hline & & Acceptable & - & - & 14 & 30.0 & \\
\hline \multirow[t]{10}{*}{12 months $(n=36)$} & & Poor/failure & - & - & - & - & \\
\hline & \multirow[t]{3}{*}{$\mathrm{Z} 250$} & Success & 36 & 100 & 7 & 19.4 & \multirow[t]{3}{*}{$<0.001$} \\
\hline & & Acceptable & - & - & 29 & 80.6 & \\
\hline & & Poor/failure & - & - & - & - & \\
\hline & \multirow[t]{3}{*}{ TBF } & Success & 36 & 100 & 33 & 91.7 & \multirow[t]{6}{*}{0.250} \\
\hline & & Acceptable & - & - & 3 & 8.3 & \\
\hline & & Poor/failure & - & - & - & - & \\
\hline & \multirow[t]{3}{*}{ FBF } & Success & 34 & 94.4 & 11 & 30.6 & \\
\hline & & Acceptable & 2 & 5.6 & 25 & 69.4 & \\
\hline & & Poor/failure & - & - & - & - & \\
\hline
\end{tabular}

Abbreviations: FBF, Filtek bulk fill; FDI, Federation Dentaire Internationale; TBF, Tetric EvoCeram bulk fill; USPHS, the United States Public Health Service. Note: The Wilcoxon test was used for comparison at the different observation times.

aSuccess: alpha (USPHS), 1 and 2 (FDI); acceptable: bravo (USPHS), 3 (FDI); failure: charlie (USPHS), 4 and 5 (FDI).

suctioning was used to maintain the area dry. Calcium hydroxide-based material was used in deep cavities. After 1 year, four restorations of the TBF group received unacceptable scores for anatomic form and marginal adaptation and two restoration due to secondary caries. The conventional resin composite inserted by an incremental technique exhibited a single failure due to secondary caries. Nevertheless, the resins tested showed similar clinical performance according to the modified USPHS criteria.

Alkurdi and Abboud ${ }^{37}$ observed full-body bulk-fill resin composites (Tetric N-Ceram Bulk Fill and Sonic Fill) for 12 months. A total-etch bonding procedure was used without lining or base materials. The overall success rate was $91.3 \%$. Of the five restoration failures, four were restored with Tetric $\mathrm{N}$-Ceram Bulk Fill (two in the marginal discoloration category and two others with persistent hypersensitivity). The success rate was $78.9 \%$ for this resin composite. The authors concluded that the single-increment technique provided acceptable clinical results similar to that of conventional resin composite. Çolak et $\mathrm{al}^{38}$ compared conventional Tetric EvoCeram resin composite with Tetric EvoCeram Bulk Fill in 74 restorations after 12 months. Deep cavities were capped with calcium hydroxide and glass ionomer cement. One restoration performed with the conventional resin failed in the marginal discoloration category. In contrast, the evaluation of 104 class-II restoration over 36 months using the USPHS criteria showed better clinical performance for Tetric EvoCeram Bulk Fill in the marginal adaptation and marginal discoloration categories compared with conventional resin composite Filtek Ultimate, due to the higher number of Bravo ratings. ${ }^{39}$

Clinical studies with a longer observation period of resin composite restorations are essential to better understand the material's performance in the oral cavity and during the function. In a retrospective 22-year follow-up study, Da Rosa Rodolpho et a ${ }^{28}$ observed an average AFR of $1.85 \%$ for composite resin restorations and good clinical performance of the material in posterior teeth. ${ }^{39-41}$ Van Dijken and Pallesen conducted clinical studies with more extended evaluation periods. ${ }^{42,43}$ Restorations prepared with flowable bulk-fill Surefil Smart Dentin Replacement (SDR) covered with conventional resin composite Ceram X mono were compared with restorations prepared only with Ceram X mono resin composite. In their 5-year follow-up, ${ }^{43}$ acceptable clinical results were obtained for the Surefil SDR restorations according to the modified USPHS criteria, with a success rate of $100 \%$ for 38 class-I restorations. Sixty-two pairs of class-II restorations received an AFR of 1.4\% for Surefil SDR and 2.1\% for those restored only with the conventional resin composite (Ceram X mono). In another study with 6 years of follow-up with these restorative 
Table 8 Comparison of the results for marginal adaptation obtained with the modified USPHS and FDI criteria

\begin{tabular}{|c|c|c|c|c|c|c|c|}
\hline \multirow[t]{3}{*}{ Evaluation } & \multirow[t]{3}{*}{ Group } & \multirow[t]{3}{*}{ Score $^{a}$} & \multicolumn{4}{|c|}{ Criteria } & \multirow[t]{3}{*}{$p$-Value } \\
\hline & & & \multicolumn{2}{|c|}{ FDI } & \multicolumn{2}{|c|}{ USPHS } & \\
\hline & & & $n$ & $\%$ & $n$ & $\%$ & \\
\hline \multirow[t]{9}{*}{ Baseline $(n=46)$} & \multirow[t]{3}{*}{$Z 250$} & Success & 38 & 82.6 & 39 & 84.8 & 0.317 \\
\hline & & Acceptable & 8 & 17.4 & 7 & 15.2 & \\
\hline & & Poor/failure & - & - & - & - & \\
\hline & \multirow[t]{3}{*}{ TBF } & Success & 40 & 87.0 & 41 & 89.1 & 0.317 \\
\hline & & Acceptable & 6 & 13.0 & 5 & 10.9 & \\
\hline & & Poor/failure & - & - & - & - & \\
\hline & \multirow[t]{3}{*}{ FBF } & Success & 39 & 84.8 & 39 & 84.8 & 1.0 \\
\hline & & Acceptable & 7 & 15.2 & 7 & 15.2 & \\
\hline & & Poor/failure & - & - & - & - & \\
\hline \multirow[t]{9}{*}{12 months $(n=36)$} & \multirow[t]{3}{*}{$\mathrm{Z} 250$} & Success & 36 & 100 & 9 & 25.0 & $<0.001$ \\
\hline & & Acceptable & - & - & 27 & 75.0 & \\
\hline & & Poor/failure & - & - & - & - & \\
\hline & \multirow[t]{3}{*}{ TBF } & Success & 34 & 94.4 & 16 & 44.4 & $<0.001$ \\
\hline & & Acceptable & 1 & 2.8 & 19 & 52.8 & \\
\hline & & Poor/failure & 1 & 2.8 & 1 & 2.8 & \\
\hline & \multirow[t]{3}{*}{ FBF } & Success & 36 & 100 & 16 & 44.4 & $<0.001$ \\
\hline & & Acceptable & - & - & 20 & 55.6 & \\
\hline & & Poor/failure & - & - & - & - & \\
\hline
\end{tabular}

Abbreviations: FBF, Filtek bulk fill; FDI, Federation Dentaire Internationale; TBF, Tetric EvoCeram bulk fill; USPHS, the United States Public Health Service. Note: The Wilcoxon test was used for comparison at the different observation times.

aSuccess: alpha (USPHS), 1 and 2 (FDI); acceptable: bravo (USPHS), 3 (FDI); failure: charlie (USPHS), 4 and 5 (FDI).

materials, ${ }^{38}$ pairs of class-II, and 15 pairs of class-I restorations were performed in 38 adults. ${ }^{34,43}$ The authors observed six failed class-II molar restorations, three in each group, and an AFR of $1.0 \%$ for both groups. It should be highlighted that the evaluation of the flowable bulk-fill resin composites is made through an indirect analysis, by analyzing the conventional resin composite that covers the flowable layer. Direct evaluation is only performed when a full-body bulk-fill resin is used.

The randomized clinical trials that evaluated full-body bulk-fill resin composites have used the USPHS criteria. ${ }^{22}$ According to Göstemeyer et $\mathrm{al}^{44}$ the USPHS criteria have shown limited sensitivity, and their categories may not fully reflect the clinical success of restorations. Using other criteria in addition to the USPHS system, clinical trials tend to detect significantly higher failure rates, more than four times those obtained with the USPHS criteria. The FDI criteria is an alternative that could be further simplified by joining scores 1 to 3 , corresponding to clinically good/satisfactory/acceptable.

In the present study, the clinical assessments used the USPHS and FDI criteria independently for evaluation. The FDI criteria were used considering the trend toward its use for evaluating restorations, while the USPHS allowed further comparison with previous studies. When comparing the corresponding categories within the USPHS and FDI criteria, significant differences were observed for roughness (USPHS)/ surface gloss/luster and roughness (FDI) and marginal adaptation. In both categories, the percentage of the "acceptable" score was significantly higher for the USPHS criteria. The two systems were equivalent to the other corresponding categories. Thus, the second null hypothesis was rejected, since there was no agreement between all the common categories between both criteria. Differences in the evaluation score parameters could explain these discrepancies. For FDI gloss/luster/roughness and USPHS roughness, the detection of a slightly dull surface (score 2 /success-FDI) could also be considered to have a slightly rough surface or to a surface with scratches, but that could be refinished (bravo/acceptable-USPHS). For marginal adaptation, the FDI criteria admit as success (score 2 ) small gaps $(<150 \mu \mathrm{m})$ and small marginal fractures removable by polishing. For USPHS, any explorer catch was considered acceptable (bravo), even if there is no visible evidence of a gap that the explorer could penetrate.

The restorations' clinical success depends on factors such as caries risk of the patient, quality of the material, extent, and location of the restoration. ${ }^{2}$ Other variables, such as parafunctional habits (bruxism), socioeconomic situation, and operator experience, also interfere directly with the restorations' longevity against the challenges to which they are exposed in the oral cavity. Many clinical trials exclude high-risk patients from the study population, especially patients with high caries and bruxism. However, these challenges are encountered by dentists in daily practice and 
require a scientific background to guide them in decision making on the adoption or rejection of new materials and techniques. ${ }^{45}$

\section{Conclusion}

The bulk-fill resin composites showed satisfactory clinical performance compared with conventional resin composite after 12 months. The percentage of the acceptable scores was significantly higher for the USPHS criteria, due to discrepancies in the score description for each criterion. Despite the positive results, further clinical studies are necessary to analyze the long-term performance of these resin composites, with longer than 12 months of follow-up time.

\section{Conflict of Interest}

None declared.

\section{References}

1 Li X, Pongprueksa P, Van Meerbeek B, De Munck J. Curing profile of bulk-fill resin-based composites. J Dent 2015;43(6):664-672

2 Van Ende A, De Munck J, Lise DP, Van Meerbeek B. Bulk-fill composites: a review of the current literature. J Adhes Dent 2017;19(2):95-109

3 Chesterman J, Jowett A, Gallacher A, Nixon P. Bulk-fill resin-based composite restorative materials: a review. $\mathrm{Br}$ Dent J 2017;222(5):337-344

4 Ilie N, Bucuta S, Draenert M. Bulk-fill resin-based composites: an in vitro assessment of their mechanical performance. Oper Dent 2013;38(6):618-625

5 Van Ende A, De Munck J, Van Landuyt KL, Poitevin A, Peumans M, Van Meerbeek B. Bulk-filling of high C-factor posterior cavities: effect on adhesion to cavity-bottom dentin. Dent Mater 2013;29(3):269-277

6 Alshali RZ, Silikas N, Satterthwaite JD. Degree of conversion of bulk-fill compared to conventional resin-composites at two time intervals. Dent Mater 2013;29(9):e213-e217

7 Didem A, Gözde Y, Nurhan Ö. Comparative mechanical properties of bulk-fill resins. Open J Comp Mat 2014;4: 117-121

8 Miletic V, Pongprueksa P, De Munck J, Brooks NR, Van Meerbeek B. Curing characteristics of flowable and sculptable bulk-fill composites. Clin Oral Investig 2017;21(4): 1201-1212

9 Jang JH, Park SH, Hwang IN. Polymerization shrinkage and depth of cure of bulk-fill resin composites and highly filled flowable resin. Oper Dent 2015;40(2):172-180

10 Fronza BM, Rueggeberg FA, Braga RR, et al. Monomer conversion, microhardness, internal marginal adaptation, and shrinkage stress of bulk-fill resin composites. Dent Mater 2015;31(12):1542-1551

11 Rocha MG, de Oliveira D, Correa IC, et al. Light-emitting diode beam profile and spectral output influence on the degree of conversion of bulk fill composites. Oper Dent 2017;42(4): 418-427

12 Moszner N, Fischer UK, Ganster B, Liska R, Rheinberger V. Benzoyl germanium derivatives as novel visible light photoinitiators for dental materials. Dent Mater 2008;24(7): 901-907

13 3M ESPE. Filtek Bulk Fill, Technical product profile. Available at: https://multimedia.3m.com/mws/media/7923210/filtekbulk-fill-flowable-restorative-technical-product-.profile. pdf. Accessed October 16, 2018
14 Flury S, Peutzfeldt A, Lussi A. Influence of increment thickness on microhardness and dentin bond strength of bulk fill resin composites. Dent Mater 2014;30(10):1104-1112

15 Bucuta S, Ilie N. Light transmittance and micro-mechanical properties of bulk fill vs. conventional resin based composites. Clin Oral Investig 2014;18(8):1991-2000

16 Ivoclar Vivadent. Scientific Documentation. Available at: http://www.ivoclarvivadent.com/en/download-center/ scientific-documentations/\#T. Accessed May 21, 2016

17 Benetti AR, Havndrup-Pedersen C, Honoré D, Pedersen MK, Pallesen U. Bulk-fill resin composites: polymerization contraction, depth of cure, and gap formation. Oper Dent 2015;40(2):190-200

18 Czasch P, Ilie N. In vitro comparison of mechanical properties and degree of cure of bulk fill composites. Clin Oral Investig 2013;17(1):227-235

19 Al-Harbi F, Kaisarly D, Bader D. El Gezawi M. Marginal integrity of bulk versus incremental fill class II composite restorations. Oper Dent 2016;41(2):146-156

20 Algamaiah H, Sampaio CS, Rigo LC, et al. Microcomputed tomography evaluation of volumetric shrinkage of bulk-fill composites in class II cavities. J Esthet Restor Dent 2017;29(2):118-127

21 Fonseca ASQS, Labruna Moreira AD, de Albuquerque PP, de Menezes LR, Pfeifer CS, Schneider LFJ. Effect of monomer type on the CC degree of conversion, water sorption and solubility, and color stability of model dental composites. Dent Mater 2017;33(4):394-401

22 Veloso SRM, Lemos CAA, de Moraes SLD, do Egito Vasconcelos BC, Pellizzer EP, de Melo Monteiro GQ. Clinical performance of bulk-fill and conventional resin composite restorations in posterior teeth: a systematic review and meta-analysis. Clin Oral Investig 2019;23(1):221-233

23 Bayraktar Y, Ercan E, Hamidi MM, Çolak H. One-year clinical evaluation of different types of bulk-fill composites. J Investig Clin Dent 2017;8(2):1-9

24 Ryge G. Clinical criteria. Int Dent J 1980;30(4):347-358

25 Turgut MD, Tekçiçek M, Olmez S. Clinical evaluation of a polyacid-modified resin composite under different conditioning methods in primary teeth. Oper Dent 2004;29(5): 515-523

26 Hickel R, Roulet JF, Bayne S, et al. Recommendations for conducting controlled clinical studies of dental restorative materials. Clin Oral Investig 2007;11(1):5-33

27 Hickel R, Peschke A, Tyas M, et al. FDI World Dental Federation - clinical criteria for the evaluation of direct and indirect restorations. Update and clinical examples. J Adhes Dent 2010;12(4):259-272

28 Da Rosa Rodolpho PA, Donassollo TA, Cenci MS, et al. 22-Year clinical evaluation of the performance of two posterior composites with different filler characteristics. Dent Mater 2011;27(10):955-963

29 Häfer M, Jentsch $H$, Haak R, Schneider H. A three-year clinical evaluation of a one-step self-etch and a two-step etch-and-rinse adhesive in non-carious cervical lesions. J Dent 2015;43(3):350-361

30 Coelho-De-Souza FH, Camargo JC, Beskow T, Balestrin MD, Klein-Júnior CA, Demarco FF. A randomized double-blind clinical trial of posterior composite restorations with or without bevel: 1-year follow-up. J Appl Oral Sci 2012;20(2): 174-179

31 Schulz KF, Altman DG, Moher D; CONSORT Group. CONSORT 2010 statement: updated guidelines for reporting parallel group randomised trials. BMJ 2010;340:c332

32 de Andrade AK, Duarte RM, Medeiros e Silva FD, et al. 30-Month randomised clinical trial to evaluate the clinical performance of a nanofill and a nanohybrid composite. J Dent 2011;39(1): $8-15$ 
33 de Andrade AK, Duarte RM, Guedes Lima SJ, Passos TA, Lima KC, Montes MA. Nanohybrid versus nanofill composite in class I cavities: margin analysis after 12 months. Microsc Res Tech 2011;74(1):23-27

34 van Dijken JW, Pallesen U. A randomized 10-year prospective follow-up of Class II nanohybrid and conventional hybrid resin composite restorations. J Adhes Dent 2014;16(6):585-592

35 Cvar JF, Ryge G. Reprint of criteria for the clinical evaluation of dental restorative materials. 1971. Clin Oral Investig 2005;9(4):215-232

36 Opdam NJ, van de Sande FH, Bronkhorst E, et al. Longevity of posterior composite restorations: a systematic review and meta-analysis. J Dent Res 2014;93(10):943-949

37 Alkurdi RM, Abboud SA. Clinical evaluation of class II composite: Resin restorations placed by two different bulk-fill techniques. J Oral Fac Sci 2016;8:34-39

38 Çolak H, Tokay U, Uzgur R, Hamidi MM, Ercan E. A prospective, randomized, double-blind clinical trial of one nano-hybrid and one high-viscosity bulk-fill composite restorative systems in class II cavities: 12 months results. Niger J Clin Pract 2017;20(7):822-831

39 Yazici AR, Antonson SA, Kutuk ZB, Ergin E. Thirty-six-month clinical comparison of bulk fill and nanofill composite restorations. Oper Dent 2017;42(5):478-485
40 Opdam NJ, Bronkhorst EM, Cenci MS, Huysmans MC, Wilson NH. Age of failed restorations: a deceptive longevity parameter. J Dent 2011;39(3):225-230

41 van Dijken JWV, Pallesen U. Clinical performance of a hybrid resin composite with and without an intermediate layer of flowable resin composite: a 7-year evaluation. Dent Mater 2011;27(2):150-156

42 van Dijken JWV, Pallesen U. Posterior bulk-filled resin composite restorations: a 5-year randomized controlled clinical study. J Dent 2016;51:29-35

43 van Dijken JWV, Pallesen U. Bulk-filled posterior resin restorations based on stress-decreasing resin technology: a randomized, controlled 6-year evaluation. Eur J Oral Sci 2017;125(4):303-309

44 Göstemeyer G, Blunck U, Paris S, Schwendicke F. Design and validity of randomized controlled dental restorative trials. Materials (Basel) 2016;9(5):372

45 Opdam NJM, Collares K, Hickel R, et al. Clinical studies in restorative dentistry: New directions and new demands. Dent Mater 2018;34(1):1-12 